\title{
Doctor-patient relationships are a perceived barrier to chiropractic use by non-Hispanic Black Americans
}

\author{
Rebecca J. Wates (1) ${ }^{1 凶}$, Jon Wilson ${ }^{2} \&$ Mark T. Pfefer ${ }^{1}$
}

Despite decades of targeted effort, the disparity in access to and utilization of health care remains high in minority populations. Not excluded is the field of chiropractic, where there is an ongoing effort to increase both non-Hispanic black (NHB) practitioners and patients in the United States. In this study, we sought to identify which barriers prevent NHB access to chiropractic care. We utilized Qualtrics $\odot$ (Qualtrics, Provo, UT) and MTurk@ (Amazon Mechanical Turk, Inc.) to administer an online survey to 3814 U.S. respondents. Among nonHispanic blacks, and compared with whites, participants were more likely to consider chiropractic care if the doctor shares their racial identity ( $37.6 \%$ vs. $17.1 \%$ ) or if referred by a family member or friend $(83.1 \%$ vs. $72.2 \%)$. NHB respondents were more likely to report barriers such as communication, transportation, or not being understood by their care provider compared with their white counterparts. Interestingly, there were no significant differences between NHB and white respondents on cost-related barriers (e.g., too expensive, insurance does not cover chiropractic). These findings highlight a need for increasing the number of practicing NHB chiropractors, through improved minority recruitment to chiropractic colleges. Further, chiropractor-driven community outreach may also begin to address the disparities in access to care for the non-Hispanic black population.

\footnotetext{
${ }^{1}$ Research Department, Cleveland University, Kansas City, Overland Park, USA. ${ }^{2}$ College of Chiropractic, Cleveland University, Kansas City, USA.

$凶_{\text {email: Rebecca.wates@cleveland.edu }}$
} 


\section{Introduction}

he United States Census Bureau projects that by the year 2044, whites will no longer be the majority racial group in America (Colby and Ortman, 2015). Despite decades of targeted effort, the disparity in access and utilization of health care remains high in minority populations (Gulley et al., 2014). Not excluded is the field of chiropractic, in which increasing minority representation (both in the patient and provider populations) remains a challenge in the United States (Brown et al., 2007).

Complementary and alternative medicine (CAM) is used with similar frequency among racial and ethnic groups: white $43.5 \%$, African American 42.6\%, Latino 40.7\%, Asian American 39\%, and Native American 39.6\% (Mackenzie et al., 2003). However, African Americans (also referred to as non-Hispanic blacks (NHB) and defined as a person having origins in any of the black racial groups of Africa (State Council of Higher Education for Virginia, 2021)), are less likely than their white counterparts to utilize chiropractic care $(3.05 \%$ versus $10.72 \%$, respectively; Sui and $\mathrm{Li}, 2011$ ). Further, based on analysis of combined data from 88,962 respondents to the 2002 and 2012 National Health Interview Surveys, the use of CAM exhibits a significant, linear decrease from $22.9 \%$ in 2002 to $19.3 \%$ in 2012 among nonHispanic black adults (Clarke et al., 2015). The same study reports significant quadratic trends for non-Hispanic white adults (34.4\% in $2002,40.2 \%$ in 2007 , and $37.9 \%$ in 2012). Additional studies have similarly found less use of CAM in NHB communities compared with their white counterparts (Kronenberg et al., 2006; Cui et al., 2012; Whedon and Song, 2012), but limited literature specifically evaluates the frequency of use of chiropractic among NHB and/or what barriers exist for this population.

Several studies have sought to determine differential chiropractic use among older persons who self-identify as NHB or white and to better characterize chiropractic care users. One small study of 183 rural older adults ( $>50$ years sought to compare CAM use between African Americans and Caucasian Americans by asking 3 research questions: (1) is there is a difference in CAM use between African American and Caucasian American older adults; (2) is there a difference in satisfaction of CAM use between AA and CA older adults; and (3) overall, what CAM modalities are being used by rural older adults (Cuellar et al., 2003). This study reports higher use of CAM products among Caucasian Americans $(19 \%, n=27)$, who were younger and more educated compared with their African American counterparts $(7.5 \%, n=3)$ and reported no difference in satisfaction of CAM use between groups. Chiropractic medicine was among the sixth most commonly used CAM products across all respondents. An investigation of CAM and prayer use among 5849 mid-life women (age 40-59) similarly found higher CAM use among white women compared with black women $(48.6 \%$ vs. $34.7 \%$, $p \leq 0.001)$ and more reported use of chiropractic among white women compared with black women $(11.2 \%$ vs. $3.1 \%, p \leq 0.001)$. Interestingly, this study found no association between educational attainment and chiropractic use. However, chiropractic was again among the most commonly used CAM methodologies across all respondents (Upchurch et al., 2010).

Two studies queried a large national dataset, from the Assets and Health Dynamics Among the Oldest Old (AHEAD) survey, to understand the use of chiropractors by older American adults and to characterize these older American adults based on their health status and modifiable risk behaviors stratified by the provider (chiropractor vs. medical doctor), respectively (Weigel et al., 2010; Wolinksy et al., 2007). In a longitudinal study of chiropractic use among 5510 respondents to the AHEAD survey
(1993-1994) and their Medicare claims (1993-2007), Weigel et al. (2010) sought to understand factors associated with chiropractic use versus nonuse. The overall prevalence of chiropractic use among respondents is $14.6 \%$, with an average annual prevalence of $4.8 \%$ (range $4.1-5.4 \%$ ) consistent with observations made by Wolinksy et al. (2007) and others. African Americans were significantly less likely to use chiropractic treatment (AOR 0.268, 95\% CI: 0.163-0.439) compared with whites. Although together these studies suggest there may be barriers that selectively affect chiropractic use among NHB individuals, there is little reported on perceived barriers to chiropractic care through the lens of the patient.

In this study, we sought to identify and compare barriers to patient access to chiropractic care between white and NHB respondents. Based upon recent work identifying barriers to chiropractic utilization among U.S. adults at large, we queried respondents on barriers including, but not limited to, transportation, communication, and attitude towards chiropractic treatment efficacy (Wilson et al., 2019). Specific to this study, we queried patients on whether doctor-patient race concordance, defined as a patient and doctor sharing an ethnic or racial identity (Meghani et al., 2009), is a barrier to accessing care. We also collected qualitative responses to more broadly understand what barriers exist for NHB access to chiropractic care.

\section{Methods}

A 16-question (6 demographic, 2 attention checks, 8 surveys), electronic survey was developed to query respondents about their perceived barriers, if any, to accessing chiropractic care. Demographic information collected included self-reported gender, age, race, ethnicity, annual household income, and geographical location (e.g., rural, urban, suburban). In the survey instrument, the term 'Black or African American' is used in alignment with the language used in the United States Census survey. In this publication, the term 'non-Hispanic Black' (NHB) is used to describe respondents who self-reported racial identity as Black or African American.

To develop the instrument questions, a survey of the literature was performed to identify common categories of barriers to chiropractic care (Weigel et al., 2010; Graham et al., 2005; Xu and Farrell, 2006; Ward et al., 2015; Barner et al., 2010; Goldstein et al., 2005). Based on this review, the following options were provided for respondents to communicate their perceived barriers relative to each category: financial (too expensive, insurance does not cover chiropractic), physical access (no available transportation, too far from your home or job), disability (problems with communication due to hearing or speech disability), doctor/ patient relationship (lack of trust for the doctor, the doctor does not understand me, prefer to see my primary care physician, cannot find a doctor that shares my ethnic/racial background), and personal circumstances, beliefs and skepticism (too busy, no need for chiropractic care, chiropractic treatment does not work, religious or cultural beliefs, problems with communication because English is not my first language). To capture any perceived barriers not captured in these categories, an 'Other' option was provided with a space for respondents to enter text. To ascertain health behaviors among the study population, respondents were queried on regular exercise, attention to diet, and regular visits to healthcare providers.

To establish face and content validity, the survey instrument was reviewed by an 8 -member panel with diverse racial and ethnic backgrounds (including 2 NHB, 1 Hispanic, and 1 Vietnamese American). The panel used a 14-point rubric for 
validation (VREP@; Simon and White, 2016) which is designed to measure face validity, construct validity, and content validity (Supplemental File; Brandon et al., 2014). Changes suggested by the panel were incorporated into the survey, and the instrument was sent back to the panel for final review before administration to study participants (Supplemental File). The survey instrument was not piloted, a limitation of this study, prior to being opened to respondents.

As described previously (Wilson et al., 2019), the instrument was delivered using the Qualtrics survey platform. Participants (the U.S. only) were recruited using Amazon's Mechanical Turk (MTurk) platform (Bohannon, 2011) and were required to agree to a statement of consent before completing the survey. Participation in the survey was voluntary, and all results were anonymous. Participants were compensated $\$ 0.10$ for completing the survey, which is consistent with the literature on the use of MTurk (Bardos et al., 2015).

Statistical analysis. To determine the number of responses needed from non-Hispanic black participants, we used the following criteria: $95 \%$ confidence level, $5 \%$ margin of error, $12.6 \%$ population proportion (based on 2015 U.S. Census data), 320.7 million population size (based on 2015 U.S. Census data). We calculated a sample size of $170 \mathrm{NHB}$ study participants. Based on previous observations in Wilson et al. (2019), we calculated that a minimum of 3800 total survey responses would be necessary to achieve our desired sample size and thus the survey remained open until at least 3800 surveys were successfully completed. Results were exported from Qualtrics into SPSS version 26 (released 2019; IBM Corporation, Armonk, NY) for analysis. Cross-tabulation was performed using self-identified race (selfreported as Black or African American or white) and each barrier was interrogated. The independent, unpaired observations were analyzed using Pearson Chi-Square; 2-sided, asymptotic significance is reported (significance indicated by $p>0.05$ ). To address our specific research question about what barriers may affect chiropractic use by NHB, only responses from those selfidentifying as Black or African American or white, based on the United States Census Bureau's defined racial categories, are reported. For clarity, respondents who selected Black or African American but did not select "Hispanic" are hereafter referred to as non-Hispanic Black (NHB). Descriptive statistics were calculated, and $p$-values are reported.

This study was reviewed and approved by the University Institutional Review Board.

\section{Results}

Using Qualtrics@ (Qualtrics, LLC) and Amazon Mechanical Turk@ (Amazon.com, Inc.), we administered an IRB-approved, online survey to national respondents over 59 days. Of the 3846 respondents who began the survey by agreeing to the consent statement, 3814 successfully completed the survey (as indicated by their correct response to the final attention check question) for a response rate of $99.2 \%$. We collected self-reported racial identity, based upon the United States Census categories of race (American Indian or Alaska Native, Asian, Black or African American, Native Hawaiian or other Pacific Islander, White or Other). Among the respondents, 45 (1.2\%) identified as American Indian or Alaska Native, 214 (5.6\%) identified as Asian, 510 (13.4\%) identified as Black or African American, seven (0.2\%) identified as Native Hawaiian or other Pacific Islander, 2939 (77.1\%) identified as White, 98 (2.6\%) identified as other (Table 1). Respondents who did not self-identify race were excluded from the analysis. Demographic information for the filtered dataset (white, Black/African American, non-Hispanic; described in the "Methods" section) is summarized in Table 2.

First, we sought to determine attitudes towards chiropractic care by querying the respondents on their attitudes in the context of previous use (Table 3) with the following response options: (A) I have been to a chiropractor, and would go back; (B) I have been to a chiropractor, and would not go back; (C) I have never been to a chiropractor, but would consider going; or (D) I have never been to a chiropractor, and would not consider going. Less nonHispanic blacks (NHB) than whites have previous experience with chiropractic $(36.0 \% \mathrm{NHB}$ vs. $44.3 \% \mathrm{~W})$; however, NHB respondents were less likely to choose not to consider going to a chiropractor if they had never been $(9.4 \% \mathrm{NHB}$ vs. $13.5 \% \mathrm{~W})$ or to express that they would not go back to a chiropractor if they had previously been $(4.7 \% \mathrm{NHB}$ vs. $8.4 \% \mathrm{~W})$, compared with white respondents.

Next, we sought to determine respondents' overall attitude towards chiropractic as a health care option. Just over $90 \%$ $(90.4 \%)$ of non-Hispanic black respondents, compared with $79.6 \%$ white respondents, considered chiropractic care to be an effective health care option (Table $4 ; p<0.001$ ). Although white respondents were more likely to have a friend or relative currently under the care of a chiropractor $(90.2 \% \mathrm{~W}$ vs. $75.7 \% \mathrm{NHB}$; $p<0.001)$, NHB respondents were more likely to consider a chiropractor if referred by a family member or friend (Table 4; $83.6 \% \mathrm{NHB}$ vs. $71.8 \% \mathrm{~W} ; p<0.001)$. Among NHB respondents, and compared with whites, respondents were more likely to consider chiropractic if they shared race concordance with the doctor (Table $4 ; 22.8 \% \mathrm{NHB}$ vs. $9.1 \% \mathrm{~W} ; p<0.001$ ).

Next, we queried respondents on whether any of the following would prevent them from seeing a chiropractor for care: too expensive; no available transportation; too far from home or job; too busy; lack of trust for the doctor; no need for chiropractic care; the doctor does not understand me; chiropractic treatment does not work; insurance does not cover chiropractic; religious or cultural beliefs; prefer to see my primary care doctor; cannot find a doctor that shares my ethnic/racial background; problems with communication because English is not my first language; problems with communication due to hearing or speech disability (Supplemental File). Overall, NHB respondents were more likely to have concerns about communication compared with white respondents. More NHB respondents were concerned about communication either due to language barrier (Table 5; $2.6 \%$ NHB vs. $0.4 \% \mathrm{~W} ; p<0.001)$ or a hearing or speech disability (Table $5 ; 2.3 \%$ NHB vs. $0.9 \% \mathrm{~W} ; p<0.05$ ). Over $10 \%$ of NHB respondents believe the doctor generally would not or does not understand them, compared with $4.89 \%$ white respondents (Table 4; $p<0.001)$. Respondents who identified as NHB were significantly more likely than white respondents to report an inability to find a doctor that shares their ethnic/racial background $(3.5 \% \mathrm{NHB}$ vs. $0.4 \% \mathrm{~W}, p<0.001)$. NHB respondents were also more likely to identify lack of transportation as a barrier to chiropractic use $(14.6 \% \mathrm{NHB}$ vs. $8.2 \% \mathrm{~W} ; p<0.001)$. More white respondents reported a preference for their primary care physician $(17.2 \% \mathrm{~W}$ vs. $11.4 \% \mathrm{NHB} ; p<0.01)$ or a belief that chiropractic care does not work $(22.5 \% \mathrm{~W}$ vs. $17.8 \% \mathrm{NHB}$, $p<0.05)$ compared with their black counterparts. There were no significant differences between black and white respondents for the other barriers listed (e.g., too expensive, $p=0.079$; too far from home or job, $p=0.132$; too busy, $p=0.799$; lack of trust for the doctor, $p=0.719$; no need for chiropractic care, $p=0.525$; insurance does not cover chiropractic, $p=0.416$; religious or cultural beliefs, $p=0.110$ ).

In addition to the pre-determined barrier options, we included a box for qualitative, "other" responses. These responses were generally sorted into one of eight categories: 
Table 1 Demographic information for all survey respondents.

Respondent demographics-all respondents, $\boldsymbol{n}(\%)$

\begin{tabular}{|c|c|c|c|c|c|c|}
\hline Gender & $\begin{array}{l}\text { Male } \\
1266(33.2)\end{array}$ & $\begin{array}{l}\text { Female } \\
2526(66.2)\end{array}$ & $\begin{array}{l}\text { Neither } \\
12(0.3)\end{array}$ & $\begin{array}{l}\text { Prefer not to answer } \\
6(0.2)\end{array}$ & $\begin{array}{l}\text { No response } \\
4(0.1)\end{array}$ & \\
\hline Age & $\begin{array}{l}<21 \text { Years } \\
106(2.8)\end{array}$ & $\begin{array}{l}21-25 \\
607(15.9)\end{array}$ & $\begin{array}{l}26-30 \\
769(20.2)\end{array}$ & $\begin{array}{l}31-35 \\
653(17.1)\end{array}$ & $\begin{array}{l}36-40 \\
469(12.3)\end{array}$ & $\begin{array}{l}>40 \text { Years } \\
1208(31.7)\end{array}$ \\
\hline Race & $\begin{array}{l}\text { American Indian/ } \\
\text { Alaska Native } \\
45(1.2)\end{array}$ & $\begin{array}{l}\text { Asian } \\
214(5.6)\end{array}$ & $\begin{array}{l}\text { African American } \\
\text { or Black } \\
510(13.4)\end{array}$ & $\begin{array}{l}\text { Native Hawaiian or } \\
\text { Pacific Islander } \\
7(0.2)\end{array}$ & $\begin{array}{l}\text { White } \\
2939(77.1)\end{array}$ & $\begin{array}{l}\text { Other } \\
98(2.6)\end{array}$ \\
\hline Ethnicity & $\begin{array}{l}\text { Hispanic, Latino or } \\
\text { Spanish } \\
264(6.9)\end{array}$ & $\begin{array}{l}\text { Not Hispanic } \\
3497 \text { (91.7) }\end{array}$ & $\begin{array}{l}\text { No response } \\
53(1.4)\end{array}$ & & & \\
\hline Annual household income & $\begin{array}{l}<\$ 25,000 \\
829(21.7)\end{array}$ & $\begin{array}{l}\$ 25-49,999 \\
1241(32.5)\end{array}$ & $\begin{array}{l}\$ 50-99,999 \\
1282(33.6)\end{array}$ & $\begin{array}{l}\$ 100,000 \text { or more } \\
457(12.0)\end{array}$ & $\begin{array}{l}\text { No response } \\
6(0.2)\end{array}$ & \\
\hline Geography & $\begin{array}{l}\text { Urban } \\
1158(30.4)\end{array}$ & $\begin{array}{l}\text { Suburban } \\
1629(42.7)\end{array}$ & $\begin{array}{l}\text { Rural } \\
1026 \text { (26.9) }\end{array}$ & $\begin{array}{l}\text { No response } \\
2(0.1)\end{array}$ & & \\
\hline
\end{tabular}

Table 2 Demographic information for selected respondents who identified racially as white or Black/African American and identified ethnically as non-Hispanic.

\begin{tabular}{|c|c|c|c|}
\hline Female & $1878(66.2)$ & $257(75.1)$ & $2135(67.1)$ \\
\hline Neither & $9(0.3)$ & $1(0.3)$ & $10(0.3)$ \\
\hline Prefer not to answer & $5(0.2)$ & $1(0.3)$ & $6(0.2)$ \\
\hline No response & $2(0.1)$ & $1(0.3)$ & $3(0.1)$ \\
\hline \multicolumn{4}{|l|}{ Age } \\
\hline $26-30$ & $555(19.6)$ & $72(21.1)$ & \\
\hline $31-35$ & $474(16.7)$ & $59(17.3)$ & \\
\hline $36-40$ & $358(12.6)$ & $47(13.7)$ & \\
\hline$>40$ Years & $1011(35.6)$ & $89(26.0)(0.3)$ & 1100 (34.6) \\
\hline No response & - & $1(0.3)$ & $1(0.03)$ \\
\hline \multicolumn{4}{|l|}{ Annual Household Income } \\
\hline No response & $4(0.1)$ & $1(0.3)$ & $5(0.2)$ \\
\hline \multicolumn{4}{|l|}{ Geography } \\
\hline Urban & $873(30.8)$ & $59(17.3)$ & 932 (29.3) \\
\hline Suburban & $750(26.4)$ & $142(41.5)$ & $892(28.1)$ \\
\hline Rural & $1214(42.8)$ & $141(41.2)$ & $1355(42.6)$ \\
\hline No response & $1(0.04)$ & - & $1(0.03)$ \\
\hline Total & 2838 & 342 & $3180(100)$ \\
\hline
\end{tabular}

Table 3 Survey respondents were queried on their prior experience with chiropractic care with four response options: 'I have been to a chiropractor, and would go back'; 'I have been to a chiropractor, and would not go back'; 'I have not been to a chiropractor, but would consider going'; 'I have not been to a chiropractor, and would not consider going'.

\section{Previous use response}

I have been to a chiropractor in the past, and would go to one in the future if needed.

I have been to a chiropractor in the past, but would not go to one again.

I have never been to a chiropractor in the past but would consider going to one in the future if

needed.

I have never been to a chiropractor in the past, and would not consider going to one.

Total
White respondents, $n(\%)$

$\begin{array}{cc}1019(35.9) & 107(31.3) \\ 239(8.4) & 16(4.7) \\ 1198(42.2) & 187(54.7) \\ 382(13.5) & 32(9.4) \\ 2838(100) & 342(100)\end{array}$


Table 4 Percent of respondents who replied affirmatively to queries on their attitudes towards chiropractic.

\begin{tabular}{|c|c|c|c|}
\hline Attitudes towards chiropractic care & \multicolumn{3}{|l|}{ Responded "Yes" } \\
\hline $\begin{array}{l}\text { To your knowledge, have any of your friends or relatives ever seen a } \\
\text { chiropractor? }\end{array}$ & $2559(90.2)$ & $259(75.7)$ & $<0.001$ \\
\hline $\begin{array}{l}\text { Would you be more likely to see a chiropractor if a friend or relative } \\
\text { suggested doing so? }\end{array}$ & $2039(71.8)$ & $286(83.6)$ & $<0.001$ \\
\hline
\end{tabular}

\section{Table 5 Summary of reported perceived barriers to chiropractic use among white and non-Hispanic black respondents.}

\begin{tabular}{|c|c|c|c|}
\hline Perceived barrier to chiropractic care & White respondents, $n$ (\%) & Non-Hispanic Black respondents, $n$ (\%) & $p$-value \\
\hline \multicolumn{4}{|l|}{ Financial } \\
\hline Too expensive & $1839(64.8)$ & $238(69.6)$ & 0.079 \\
\hline Insurance doesn't cover chiropractic & $1576(55.5)$ & $182(53.2)$ & 0.416 \\
\hline No available transportation & $234(8.2)$ & $50(14.6)$ & $<0.001$ \\
\hline Too far from your home or job & $480(16.9)$ & $69(20.2)$ & 0.132 \\
\hline \multicolumn{4}{|l|}{ Disability } \\
\hline Lack of trust for the doctor & $630(22.2)$ & $73(21.3)$ & 0.719 \\
\hline The doctor doesn't understand me & $136(4.8)$ & $37(10.8)$ & $<0.001$ \\
\hline Prefer to see my primary care physician & $487(17.2)$ & $39(11.4)$ & $<0.01$ \\
\hline Can't find a doctor that shares my ethnic/racial background & $10(0.4)$ & $12(3.5)$ & $<0.001$ \\
\hline \multicolumn{4}{|l|}{ Personal circumstances, beliefs, skepticism } \\
\hline Too busy & $715(25.2)$ & $84(24.6)$ & 0.799 \\
\hline
\end{tabular}
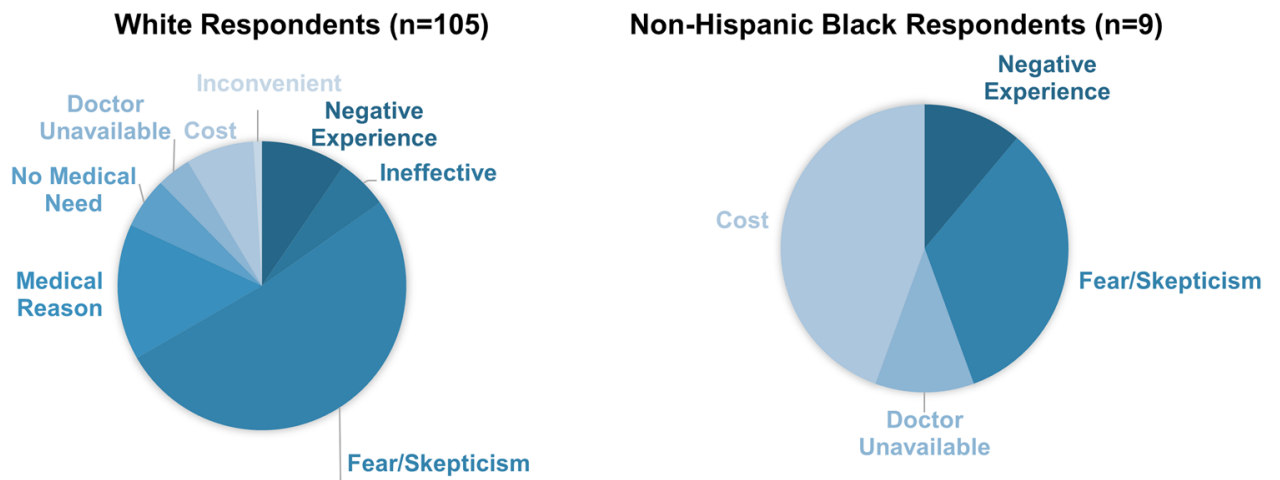

Fig. 1 Self-reported perceived barriers to chiropractic use. Responses to a qualitative question on perceived barriers to chiropractic use are tallied reported.

(1) previous negative experience, (2) chiropractic is ineffective, (3) fear or skepticism, (4) medical reason for avoiding chiropractic, (5) no medical need for chiropractic, (6) doctor unavailable, (7) cost, and (8) inconvenience. NHB respondents' write-in barriers were assigned to 4 of those 8 categories (listed in order of prevalence among NHB respondents): cost, fear and/or skepticism, unavailability of a doctor, or negative experience (Fig. 1).

\section{Discussion}

Based on the changing demographics of American adults and in consideration of the ongoing conversation on the role of chiropractic treatment (Qaseem et al., 2017; Parkin-Smith et al., 2015) as a mainstream treatment for musculoskeletal disorders, we sought to identify barriers to adult, non-Hispanic Black (NHB) patient access to chiropractic care in the United States. Our goal is to add to the body of chiropractic research knowledge that may 
improve access to and utilization of chiropractic treatment by non-Hispanic blacks who tend to utilize chiropractic at a lower rate when compared with their white counterparts (Sui and $\mathrm{Li}$, 2011).

To achieve this goal, a survey was administered to a representative sample of U.S. adults on their attitudes towards chiropractic and barriers that may hinder their decision to seek chiropractic care. To specifically address the question about which, if any, barriers may prevent black/African Americans from seeking chiropractic care, respondents were requested to select their self-identified race. Self-identified race distribution of survey respondents was comparable to the United States population's race distribution suggesting that our sample population is racially representative of U.S. citizens. Next, total responses were filtered based on self-selected race, and responses between non-Hispanic black (NHB)/African American respondents and white respondents were compared. Similar to other studies (Brown et al., 2007; Sui and Li, 2011; Barner et al., 2010; Weeks et al., 2016), we found that non-Hispanic black respondents were less likely than their white counterparts to have previous experience with chiropractic treatment. Interestingly, NHB respondents were more likely to consider chiropractic in the absence of prior experience and were more likely to return to a chiropractor if they did had prior experience, compared with their white counterparts.

Among respondents to this survey, women were overrepresented (66.2\% compared with $33.3 \%$ male respondents). Several previous studies have also reported higher use of CAM among women in comparison with men. One study (Honda and Jacobson, 2005) performed multiple logistic regression analyses on a dataset produced through the administration of the Midlife Development in the United States Survey (MIDUS). This instrument (a 3-minute phone interview, followed by 2 mailed questionnaires) was administered to 4242 adults (aged 24-75) residents of the contiguous United States. Among 1640 respondents who reported having used any CAM modality within 12 months prior to query, $62.5 \%$ of women compared with $37.5 \%$ of men reported any use of CAM. Findings within this publication related to psychological factors influencing the use of CAM among U.S. adults, while outside the scope of this discussion, are interesting and worthy of review. A different comparison, of CAM use among a convenience sample of 183 white and African American elders residing in rural communities in Mississippi, similarly reported higher use of any CAM modality in women compared with men ( $76 \%$ vs. $24 \%)$. However, since the study does not report demographic data of those who did not report CAM use $(n=195$; total respondents $=378)$ it is unclear whether the difference is due to querying a nonrepresentative sample (Cuellar et al., 2003).

A California Health Interview Survey 2001 (CHIS 2001) follow-up survey to reassess respondents' health and illness status and query CAM use (CHIS-CAM) found an increased prevalence of any CAM use among women compared with men (OR 1.39; $1.15,1.6795 \% \mathrm{CI} ; p<0.001)$. However, there was no difference in the prevalence of chiropractic use between the groups (OR 1.08; $0.85,1.3795 \%$ CI). More recently, an analysis of the 2012 National Health Interview Survey (NHIS) of 34,525 participants reported that women were more to report being a CAM users compared with men $(59.1 \%$ vs. $40.0 \%)$. Further, female CAM users were more likely to use CAM for perceived benefits to overall wellness and preventive care while men were more likely to report using CAM modalities to improve physical or athletic performance (Chao and Wade, 2008). These and others' conclusions (Kronenberg et al., 2006; Huff and Tingley, 2015) highlight the complexities of gender and other socioeconomic factors on health decisions and the need for further study to further clarify the impact of gender on chiropractic use.
Additionally, the dataset discussed here reflects an oversampling of respondents under 40 years of age compared with the U.S. population. The use of age groups that are biased towards those under 40 and not aligned with commonly used aged groups (e.g. United States Census Bureau) also renders a nuanced evaluation of these data difficult. This observation is unsurprising and represents a limitation of administering online surveys previously observed in the literature (Huff and Tingley, 2015; Sheehan, 2017). Furtherance of this work will leverage these findings to refine study sample selection.

Considering our and others' finding that NHB respondents were less likely to have prior experience with chiropractic compared with white respondents (Whedon and Song, 2012; Wilson et al., 2019; Weeks et al., 2016), we queried all respondents on a number of barriers to access to chiropractic are including barriers related to doctor-patient race concordance, healthcare costs (including transportation or lack thereof), trust/mistrust of chiropractic treatments and/or personal beliefs, and communicationsrelated barriers. Among the seven barriers where white and NHB responses differed significantly, five were barriers that NHB respondents were more likely to report as preventing their access to chiropractic care compared with their white counterparts: doctor-patient race concordance, communication (due to language barriers), communication (due to disability), transportation, or lack of understanding on the part of the doctor. Although doctor-patient race concordance, that is sharing of racial and/or ethnic background of the doctor and patient, has been well studied in medicine there is a dearth of literature on the subject in chiropractic. One review has comprehensively reviewed gaps in both cultural competences across chiropractic doctors of all backgrounds and gaps in minority representation in the chiropractic workforce (Johnson and Green, 2012). Addressing these areas may lead to an increase in chiropractors who identify as racial and/or ethnic minorities, providing greater patient access to race concordant doctors. Further, the increased representation of underrepresented minorities may increase patient access to multilingual chiropractors.

Over $10 \%$ of NHB respondents selected "The doctor doesn't understand me" as a barrier to accessing chiropractic care. The language chosen intended to represent patients who may not feel heard by their doctor, as opposed to patients who feel they are not understood due to a language barrier; however, it is possible that ambiguity in the phrasing leads to misinterpretation and incorrect selection (or lack of selection) of this barrier. It is important to note that while $10.4 \%$ of NHB respondents selected this barrier, only 2.7 of NHB respondents selected the "Communication (English not primary language)" barrier. This suggests respondents understood the context of this barrier and selected it appropriately based on their perceptions. Some patients may hold cultural and/or religious beliefs, questions, and fears and feel a lack of empathy for said concerns. As noted above, two approaches to resolving these barriers are incorporating cultural competence training into all stages of chiropractic education and training a more diverse chiropractic workforce (Callender, 2006; Christensen et al., 2015).

Socioeconomic and disability-related barriers commonly prevent patient access to health care leading to worse outcomes, and elimination of such barriers has been postulated as a contributing mechanism to eliminate disparities in health (Andrulis, 1998; Arpey et al., 2017). Our findings suggest transportation is one socioeconomic barrier to access to chiropractic care by NHB patients; chiropractors may seek community resources to aid patients with transportation to and from appointments. Adoption and implementation of processes to aid in communicating and providing service for patients with disabilities (e.g., hearing, eyesight) and accessible equipment and facilities may also 
improve access to care for these patients (Harmer, 1999; Yee and Breslin, 2010).

Limitations. The survey instrument presented in this study was reviewed for face, content, and construct validity using expert review panel methodology; criterion validity requires further study. The survey instrument was not piloted prior to administration to respondents. Sampling across groups was limited, and subsequently, some groups were represented disproportionately. Participants were more likely to be white and non-Hispanic, younger, and female with a moderate household income.

\section{Conclusion}

The chiropractic profession is the largest CAM profession and one of the largest licensed health care professions in the United States (Meeker and Haldeman, 2002; Cooper and McKee, 2003). Chiropractic providers render a large amount of care to underserved and rural populations (Smith and Carber, 2002). Yet, chiropractors see minority patients at less than half the rate of whites which raises concerns; reasons for this discrepancy are unknown. Further, whether the chiropractic profession is prepared (e.g., have a diverse workforce that is providing culturally competent care) to meet emerging demographic changes remains a topic of discussion (Johnson and Green, 2012). Lack of publications that address issues of diversity in the chiropractic profession demonstrate that there is significant room for growth and understanding (Johnson et al., 2012). The chiropractic profession has an obligation to increase the number of minority faculty and students within their programs. The profession should also make a concerted effort to reach out to minority communities about access to care and provide evidence-based information about benefits, costs, and safety of conservative, non-drug interventions for common, disabling spine-related problems.

\section{Data availability}

The datasets generated during and/or analyzed during the current study are available in the Harvard Dataverse repository, https:// doi.org/10.7910/DVN/WL5LTM.

Received: 8 October 2020; Accepted: 5 October 2021; Published online: 02 November 2021

\section{References}

Andrulis DP (1998) Access to care is the centerpiece in the elimination of socioeconomic disparities in health. Ann Intern Med 129(5):412-6

Arpey NC, Gaglioti AH, Rosenbaum ME (2017) How socioeconomic status affects patient perceptions of health care: a qualitative study. J Prim Care Community Health 8(3):169-75

Bardos J, Hercz D, Friedenthal J et al. (2015) A national survey on public perceptions of miscarriage. Obstet Gynecol 125(6):1313-20

Barner JC, Bohman TM, Brown CM et al. (2010) Use of complementary and alternative medicine (CAM) for treatment among African-Americans: a multivariate analysis. Res Soc Adm Pharm 6(3):196-208

Bohannon J (2011) Social science for pennies. Science 334(6054):307

Brandon DM, Long JH, Loraas TM et al. (2014) Online instrument delivery and participant recruitment services: emerging opportunities for behavioral accounting research. Behav Res Account 26(1):1-23

Brown CM, Barner JC, Richards KM et al. (2007) Patterns of complementary and alternative medicine use in African Americans. J Altern Complement Med 13(7):751-8

Callender A (2006) Recruiting underrepresented minorities to chiropractic colleges. J Chiropr Educ 20(2):123-7

Chao MT, Wade CM (2008) Socioeconomic factors and women's use of complementary and alternative medicine in four racial/ethnic groups. Ethn Dis 18(1):65-71
Christensen MG, Hyland JK, Goertz CM et al. (2015) The chiropractic practitioner. In: Christensen MG (ed) Practice analysis of chiropractic. National Board of Chiropractic Examiners, Greeley, p. 78

Clarke TC, Black LI, Stussman BJ et al. (2015) Trends in the use of complementary health approaches among adults: United States, 2002-2012. Natl Health Stat Rep 79:1-16

Colby SL, Ortman JM (2015) Projections of the size and composition of the U.S. population: 2014 to 2060. United States Census Bureau. https:// www.census.gov/content/dam/Census/library/publications/2015/demo/p251143.pdf. Accessed 17 Aug 2017

Cooper RA, McKee HJ (2003) Chiropractic in the United States: trends and issues. Milbank Q 81(1):107-38

Cuellar N, Aycock T, Cahill B et al. Complementary and alternative medicine (CAM use by African American (AA) and Caucasian American (CA) older adults in a rural setting: a descriptive, comparative study. BMC Complement Altern Med 3:8

Cui Y, Hargreaves MK, Shu X-O et al. (2012) Prevalence and correlates of complementary and alternative medicine services use in low-income African Americans and Whites: a report from the southern community cohort study. J Altern Complement Med 18(9):844-9

Goldstein MS, Brown ER, Ballard-Barbash R et al. (2005) The use of complementary and alternative medicine among California adults with and without cancer. eCAM 2(4):557-565

Graham RR, Ahn AC, Davis RB et al. (2005) Use of complementary and alternative medical therapies among racial and ethnic minority adults: results from the 2002 National Health Interview Survey. J Natl Med Assoc 97(4):535-45

Gulley SP, Rasch EK, Chan L (2014) Difference, disparity, and disability: a comparison of health, insurance coverage, and health service use on the basis of race/ethnicity among US adults with disabilities, 2006-2008. Med Care 52(10 Suppl 3):S9-16

Harmer L (1999) Health care delivery and deaf people: practice, problems, and recommendations for change. J Deaf Stud Deaf Educ 4(2):73-110

Higher Ed Data Glossary (2021) State Council of Higher Education for Virginia, Richmond. https://research.schev.edu/info/Glossary.Black-or-AfricanAmerican-Black-non-Hispanic. Accessed 23 Jun 2021

Honda K, Jacobson JS (2005) use of complementary and alternative medicine among United States adults: the influences of personality, coping strategies and social support. Prev Med 40:46-53

Huff C, Tingley D (2015) "Who are these people?" Evaluating the demographic characteristics and political preferences of MTurk survey respondents. Res Politics 2(3):1-12

Johnson C, Killinger LZ, Christensen MG et al. (2012) Multiple views to address diversity issues: an initial dialog to advance the chiropractic profession. J Chiropr Humanit 19(1):1-11

Johnson CD, Green BN (2012) Diversity in the chiropractic profession: preparing for 2050. J Chiropr Educ 26(1):1-13

Kronenberg F, Cushman LF, Wade CM et al. (2006) Race/ethnicity and women's use of complementary and alternative medicine in the United States: results of a national survey. Am J Public Health 96(7):1236-42

Mackenzie ER, Taylor L, Bloom BS et al. (2003) Ethnic minority use of complementary and alternative medicine (CAM): a national probability survey of CAM utilizers. Altern Ther Health Med 9(4):50-6

Meeker WC, Haldeman S (2002) Chiropractic: a profession at the crossroads of mainstream and alternative medicine. Ann Intern Med 136(3):216-27

Meghani SH, Brooks JM, Gipson-Jones T et al. (2009) Patient-provider race-concordance: does it matter in improving minority patients' health outcomes? Ethn Health 14(1):107-30

Parkin-Smith GF, Amorin-Woods LG, Davies SJ et al. (2015) Spinal pain: current understanding, trends and the future of care. J Pain Res 8:741-52

Qaseem A, Wilt TJ, McLean RM et al. (2017) Noninvasive treatments or acute, subacute, and chronic low back pain: a clinical practice guideline from the American College of Physicians. Ann Intern Med 166(7):514-30

Sheehan KB (2017) Crowdsourcing research: data collection with Amazon's Mechanical Turk. Commun Monogr 85(1):140-156

Simon MK, White J (2016) Survey/interview validation rubric for an expert panel. Dissertation Recipes. http://www.dissertationrecipes.com/surveyinterviewvalidation-rubric-for-an-expert-panel/. Accessed 11 Apr 2016

Smith M, Carber L (2002) Chiropractic health care in health professional shortage areas in the United States. Am J Public Health 92(12):2001-9

Sui D, Li L (2011) Trends in the use of complementary and alternative medicine in the United States: 2002-2007. J Health Care Poor Underserved 22(1):296-310

Upchurch D, Dye C, Chyu L et al. (2010) Demographic, behavioral, and health correlates of complementary and alternative medicine and prater use among midlife women: 2002. J Women's Health 19(1):23-30

Ward J, Humphries K, Coats J et al. (2015) Attributes of non-Hispanic blacks that use chiropractic health care: a survey of patients in Texas and Louisiana. J Chiro Med 14:15-23 
Weeks WB, Goertz CM, Meeker WC et al. (2016) Characteristics of US adults who have positive and negative perceptions of doctors of chiropractic and chiropractic care. J Manip Physiol Ther 39(3):150-7

Weigel P, Hockenberry JM, Bentler SE et al. (2010) A longitudinal study of chiropractic use among older adults in the United States. Chiropr Osteopat 18:34

Whedon JM, Song Y (2012) Racial disparities in the use of chiropractic care under Medicare. Altern Ther Health Med 18(6):20-6

Wilson J, Wates RJ, Sandefur R et al. (2019) Feasibility using Amazon Mechanical Turk for online surveys of attitudes and perceptions of chiropractic health care in the United States. J Manip Physiol Ther 42(2):96-103

Wolinksy FD, Liu L, Miller TR et al. (2007) The use of chiropractors by older adults in the United States. Chiropr Osteopat 15:12

$\mathrm{Xu}$ KT, Farrell TW (2006) The complementarity and substitution between unconventional and mainstream medicine among racial and ethnic groups in the United States. Health Serv Res 42(2):811-826

Yee S, Breslin ML (2010) Achieving accessible health care for people with disabilities: why the ADA is only part of the solution. Disabil Health J 3(4):253-61

\section{Acknowledgements}

The authors wish to acknowledge the expert panel members who reviewed the survey instrument. The authors also wish to acknowledge Cleveland University - Kansas City for providing funding to support this research project.

\section{Competing interests}

The authors declare no competing interests.

\section{Ethical approval}

The questionnaire and methodology for this study was reviewed by the Institutional Review Board of Cleveland University - Kansas City and determined it exempt on the basis of it being an anonymous survey.

\section{Informed consent}

Informed consent was obtained from each participant prior to accessing the survey instrument.

\section{Additional information}

Supplementary information The online version contains supplementary material available at https://doi.org/10.1057/s41599-021-00936-1.

Correspondence and requests for materials should be addressed to Rebecca J. Wates.

Reprints and permission information is available at http://www.nature.com/reprints

Publisher's note Springer Nature remains neutral with regard to jurisdictional claims in published maps and institutional affiliations.

(c) (i) Open Access This article is licensed under a Creative Commons Attribution 4.0 International License, which permits use, sharing, adaptation, distribution and reproduction in any medium or format, as long as you give appropriate credit to the original author(s) and the source, provide a link to the Creative Commons license, and indicate if changes were made. The images or other third party material in this article are included in the article's Creative Commons license, unless indicated otherwise in a credit line to the material. If material is not included in the article's Creative Commons license and your intended use is not permitted by statutory regulation or exceeds the permitted use, you will need to obtain permission directly from the copyright holder. To view a copy of this license, visit http://creativecommons.org/ licenses/by/4.0/.

(c) The Author(s) 2021 